\title{
Avaliação reológica sob diferentes temperaturas de pastas cimentícias aditivadas com diferentes tipos de aditivos superplastificantes à base de policarboxilatos
}

\author{
Rheological evaluation at varied temperatures \\ of cementitious pastes containing different types \\ of polycarboxylate superplasticizers admixtures
}

Ana Rita Damasceno Costa ${ }^{1}$, Angela Borges Masuero ${ }^{2}$, Jardel Pereira Gonçalves ${ }^{1}$

\footnotetext{
${ }^{1}$ Programa de Pós-graduação em Engenharia Civil, Construção Civil e Materiais, PPEC/UFBA, Escola Politécnica, Rua Prof. Aristides Novis n ${ }^{\circ}$ 02, Federação, Salvador, Bahia, Brasil.

${ }^{2}$ Programa de Pós-graduação em Engenharia Civil, Construção e Infraestrutura, PPGCI/UFRGS, Escola de Engenharia, Av. Osvaldo Aranha, ${ }^{\circ}$ 99, Cidade Baixa, Porto Alegre, Rio Grande do Sul, Brasil.

e-mail: rita.damasceno@ufba.br, angela.masuero@ufrgs.br,jardelpg@ufba.br
}

\section{RESUMO}

O estudo dos parâmetros reológicos das pastas cimentícias pode fornecer informações importantes sobre o desempenho dos concretos frescos nos quais elas serão aplicadas. Nesse contexto, este trabalho visa estudar os efeitos da temperatura nos parâmetros reológicos de pastas cimentícias aditivadas com superplastificantes. Também é abordada a análise do efeito do tipo de cimento, bem como o estudo da ação de superplastificantes à base de policarboxilato considerando sua função e os seus teores na mistura. As pastas foram avaliadas pelo ensaio de mini-abatimento e os parâmetros de tensão de escoamento, viscosidade plástica e indicador de tixotropia foram estimados a partir do ensaio de reometria rotacional e aplicação dos modelos de fluidos de Bingham e Herschel-Bulkley. Os resultados indicaram que o aumento da temperatura levou a uma redução das tensões de escoamento, viscosidades plásticas e tixotropia das pastas. Efeito semelhante ocorreu após o incremento do teor de aditivo até a dosagem de saturação. Para as formulações com o aglomerante de maior teor de pozolana as tensões de escoamento e viscosidades plásticas foram superiores em até 80 e $70 \%$, respectivamente. Os dados reológicos indicam que aditivos de diferentes funções (abertura, espalhamento e multifuncional), embora apresentem a mesma base, influenciam de forma distinta os parâmetros reológicos e plasticidade das pastas cimentícias.

Palavras-chave: Reologia. Cimentos. Superplastificantes. Efeitos da temperatura.

\section{ABSTRACT}

The study of the rheological parameters of the cementitious pastes can provide important information on the performance of fresh concretes in which they will be applied. In this context, this paper aims to study the effects of temperature on the rheological parameters of cementitious pastes added with superplasticizers. It is approached the analysis of the effect of type of cement in pastes rheological behavior, as well as the study of the action of superplasticizers based on polycarboxylate considering its function and its contents in the mixture. The pastes were evaluated by the mini-slump test and the parameters of yield stress, plastic viscosity and thixotropy were estimated by the rotational rheometry test and application of Bingham and HerschelBulkley fluid models. The results indicated that the increase in temperature led to a reduction of the yield stresses, plastic viscosities and thixotropy of pastes. A similar effect occurred after increasing the admixture content up to the saturation content. For formulations with the binder of highest content of pozzolan, the yield stress and plastic viscosities were higher by up to 80 and $70 \%$, respectively. The rheological data indicate that admixtures of different functions (spreading, maintenance and multifunctional), although having the same base, influence in a different way the rheological parameters and plasticity of cementitious pastes. 
Keywords: Rheology. Cements. Superplasticizers. Temperature effects.

\section{INTRODUÇÃO}

A trabalhabilidade do concreto é influenciada por sua composição, como por exemplo, relação água/aglomerante, granulometria, fator de forma e teor dos seus agregados [1]. Por outro lado, a trabalhabilidade também é impactada pelas propriedades reológicas da pasta cimentícia, que por sua vez depende de fatores como tipo de cimento, relação água/aglomerante, uso de adições, aditivos químicos, condições ambientais, entre outros [2].

Em temperaturas próximas a $25^{\circ} \mathrm{C}, \mathrm{o}$ concreto geralmente apresenta moderada perda de fluidez, porém, mantém-se trabalhável por tempo suficiente para transporte, manipulação e moldagem [3]. No entanto, em temperaturas mais elevadas $\left(30\right.$ a $\left.50{ }^{\circ} \mathrm{C}\right)$, a aceleração dos processos de hidratação do cimento e a perda de água por evaporação reduzem a trabalhabilidade do material, podendo dificultar o processo de manipulação e aplicação [4].

O aditivo superplastificante (SP) é um produto desenvolvido para fornecer ao concreto uma redução da demanda de água aprimorando a trabalhabilidade, fluidez e plasticidade. Superplastificantes com base de policarboxilatos são incorporados em materiais de base cimentícia devido ao seu efeito dispersante [5]. A estrutura molecular do policarboxilato é formada por uma cadeia principal linear com ramificações de carboxilatos e éteres. Esta configuração faz com que os grupos carboxilatos da molécula sejam adsorvidos no grão de cimento, ocasionando assim uma dispersão por repulsão eletrostática, mas também (e principalmente) uma repulsão estérica causada pelas longas cadeias laterais dos grupos éteres [6]. No processo inicial de hidratação os policarboxilatos são rapidamente adsorvidos pela superfície dos hidratos resultantes da hidratação do $\mathrm{C}_{3} \mathrm{~A}\left(3 \mathrm{CaO} . \mathrm{Al}_{2} \mathrm{O}_{3}\right)$ presente no cimento [7]. Tal processo pode ocorrer de forma definitiva ou transitória e reduz a disponibilidade do SP na suspensão, aumentando o percentual necessário para saturação do aditivo na pasta [8].

Aditivos superplastificantes de policarboxilato éter consistem em uma cadeia central, contendo grupos ácidos, com ramificações que lhes conferem a estrutura característica de pente. $\mathrm{O}$ pH ácido da estrutura molecular geralmente é modificado por um tratamento químico que busca neutralizar seu potencial hidrogeniônico e tornar sua manipulação mais segura. $\mathrm{O}$ pH do produto varia em função do método neutralizador aplicado por seu fabricante e está associado a diferentes efeitos no desempenho reológico de materiais cimentícios. GOETZ-NEUNHOEFFER et al. [9] apontam uma relação entre o pH do aditivo e o processo de formação dos cristais de etringita na matriz, principalmente no que diz respeito à razão comprimento/largura dos cristais da fase hidratada. CHOMYN e PLANK [10] relacionaram a eficácia da dispersão de superplastificantes aos seus respectivos potenciais hidrogeniônicos. Os autores verificaram que SPs ácidos atuam como fortes agentes modificadores da cristalização de etringita, reduzindo a sua formação no período inicial da hidratação e exigindo uma dosagem mais baixa. Deve-se considerar, no entanto, que apesar da elevada acidez contribuir para eficiência do produto, há um risco potencial para a saúde dos profissionais que o utilizam e a necessidade de tanques e embalagens de armazenamento específicas para soluções ácidas.

A duração do efeito do SP decorre de sua forma molecular. Um encurtamento da cadeia principal da molécula ou incremento no número de cadeias laterais torna mais efetivo o tempo e o efeito de dispersão induzido [11]. De forma semelhante, o peso molecular é diretamente proporcional à adsorção granular e tem consequência direta no aprimoramento da fluidez da mistura. As cadeias do polímero agem afastando os grãos do cimento, reduzindo o atrito interpartícula e o consumo de água, aumentando a manutenção da fluidez ao longo do tempo e, em alguns casos, prolongando o tempo de pega [12]. Por conseguinte, o uso de aditivos superplastificantes tem considerável influência nas propriedades reológicas das pastas cimentícias [13].

O estudo dos parâmetros reológicos das pastas cimentícias pode fornecer informações importantes sobre o desempenho dos concretos frescos nos quais elas serão aplicadas. Quando adequadamente mensurados, podem ser utilizados para controlar os teores de adições químicas e minerais incorporadas à mistura de concreto [14]. BRITO et al. [15] avaliaram o desempenho reológico de pastas de geopolímero e observaram um aumento da tensão de escoamento e viscosidade aparente associada ao incremento da razão $\mathrm{SiO}_{2} / \mathrm{Al}_{2} \mathrm{O}_{3}$ nas composições. SÉRGIO et al. [16] analisaram pastas de cimento Portland com adição de metacaulim e resíduo de tijolo cerâmico e identificaram que os fatores água/sólido, índice de empacotamento das partículas e granulometria são os principais intervenientes nos parâmetros reológicos das misturas.

A reometria rotacional é uma técnica geralmente aplicada para estudo de pastas cimentícias, mas também é vastamente utilizada para avaliação e dosagem de concretos autoadensáveis (CAA) e concretos de alto desempenho (CAD). Ao avaliar a compatibilidade entre seus resultados quando comparados a outras técnicas de avaliação pontual no estudo do CAD, MACIEL et al. [17] verificaram uma boa correlação entre a tensão 
de escoamento obtida pela reometria e a viscosidade aparente estimada pela técnica de Pashias. MENDES et al. [18] também reportaram uma relação satisfatória entre a viscosidade plástica do CAA e a viscosidade aparente obtida pela técnica do funil V. A análise dos parâmetros reológicos por reometria rotacional também vem sendo aplicada para o estudo do desempenho de CAA e CAD aditivados com superplastificantes e contendo diferentes tipos de filler [19], resíduos de agregado reciclado [20] e sílica ativa [21].

As propriedades reológicas de pastas cimentícias são significativamente afetadas pela variação de temperatura, tempo de mistura, dosagem e tempo após o contato com a água [4, 22]. A elevação da temperatura até $50{ }^{\circ} \mathrm{C}$ pode atuar tanto aumentando a tensão de escoamento e viscosidade plástica [23] quanto diminuindo os valores destes parâmetros [24]. No entanto, há um consenso de que, frente a variações de temperatura, uma maior estabilidade dos parâmetros reológicos pode ser obtida incrementando as relações mássicas superplastificante / cimento ou água / cimento [23, 24].

Os parâmetros reológicos de pastas cimentícias com diferentes tipos de aditivos superplastificantes têm sido estimados satisfatoriamente por modelos matemáticos baseados nas propriedades físico-químicas de suas matérias-primas, bem como condição de aplicação [23-26]. Para superplastificantes compostos por policarboxilatos, ERZENGIN et al. [27] e HE et al. [28] observaram que o aumento da densidade da cadeia carboxílica é o principal fator determinante no potencial de dispersão destes aditivos, bem como da estabilidade e conservação das propriedades reológicas ao longo do tempo. No entanto, há uma limitação nos estudos do comportamento reológico de pastas com tipos de cimento distintos utilizados no mercado brasileiro, bem como diferentes aditivos superplastificantes à base de policarboxilato (quanto à função de abertura ou espalhamento) frente a variações de temperatura. Portanto, o objetivo principal deste trabalho é analisar os efeitos da temperatura nos parâmetros reológicos (tensão de escoamento, viscosidade plástica e tixotropia) estimados pela reometria rotacional aplicada em pastas cimentícias aditivadas com superplastificantes. Também é abordada a análise do efeito do tipo de cimento no comportamento reológico das pastas, bem como o estudo da ação de três superplastificantes à base de policarboxilatos, considerando seu tipo de função e os seus teores na mistura.

\section{MATERIAIS E MÉTODOS}

\subsection{Materiais}

Foram avaliadas as propriedades reológicas de pastas cimentícias aditivadas com superplastificantes com base de policarboxilatos de diferentes fabricantes. A relação água/aglomerante foi fixada em 0,30. As temperaturas de avaliação foram de 25,35 e $45{ }^{\circ} \mathrm{C}$, buscando simular a temperatura das matérias-primas em um dia de clima ameno, quente e muito quente, respectivamente. Os cinco teores de aditivo superplastificante com relação à massa de cimento $(\mathrm{SP} / \mathrm{C})$ foram aplicados na faixa de 0,4 até $1,0 \%$. Os teores foram selecionados de modo que estivessem contidos na intersecção entre as faixas de teores recomendados pelos três fabricantes e com um distanciamento fixo de $0,15 \%$ para atender à quantidade de pontos desejada para a análise.

\subsubsection{Cimentos}

Os aglomerantes utilizados nas misturas foram cimentos Portland dos tipos V de Alta Resistência Inicial (CPV ARI), equivalente ao Tipo III da norma americana ASTM C 150 [29], e IV (CP IV), correspondente ao Tipo IP da norma ASTM C 595 [30], de acordo com a norma brasileira NBR 16697 Cimento Portland - Requisitos [31]. O primeiro por ser o cimento com menor teor de adições comercializado no Brasil e o segundo por ter um alto teor de pozolana $(<50 \%$ de cinza volante). Suas caracterizações físicas e químicas são apresentadas nas Tabelas 1 e 2, respectivamente.

Tabela 1: Caracterização física dos cimentos.

\begin{tabular}{c|c}
\hline MATERIAL & MASSA ESPECÍFICA $\left[\mathbf{g} / \mathbf{c m}^{3}\right]$ \\
\hline CP IV & 2,61 \\
\hline CP V ARI & 3,12 \\
\hline
\end{tabular}

Tabela 2: Composição química dos cimentos.

\begin{tabular}{l|c|c|c|c|c|c|c|c|c}
\hline MATERIAL & $\mathrm{CaO}$ & $\mathrm{SiO}_{2}$ & $\mathrm{Al}_{2} \mathrm{O}_{3}$ & $\mathrm{Fe}_{2} \mathrm{O}_{3}$ & $\mathrm{SO}_{3}$ & $\mathrm{CO}_{2}$ & $\mathrm{~K}_{2} \mathrm{O}$ & $\mathrm{MgO}$ & OUTROS \\
\hline
\end{tabular}




\begin{tabular}{c|c|c|c|c|c|c|c|c|c}
\hline CP IV & 41,45 & 28,02 & 14,29 & 4,09 & 4,06 & 3,83 & 1,84 & 0,88 & 1,54 \\
\hline CP V ARI & 68,85 & 12,80 & 3,73 & 4,89 & 4,69 & 1,36 & 1,47 & 1,06 & 1,15 \\
\hline
\end{tabular}

\subsubsection{Superplastificantes}

Foram utilizados três aditivos superplastificantes líquidos à base de policarboxilatos e de diferentes fornecedores, doravante nomeados Fabricantes A, B e C. As especificações são apresentadas na Tabela 3, de acordo com as fichas técnicas fornecidas por seus fabricantes. O aditivo A apresenta função de abertura/espalhamento, contendo em sua composição $75 \%$ de cadeias policarboxilato-éster, enquanto que o aditivo B possui função de manutenção, contendo $75 \%$ de cadeias policarboxilato-éster. $\mathrm{O}$ aditivo $\mathrm{C}$ é um superplastificante multifuncional de função intermediária visando promover a robustez dos aditivos clássicos unida às propriedades de dispersão dos superplastificantes.

Tabela 3: Aditivos superplastificantes.

\begin{tabular}{c|c|c|c|c}
\hline IDENTIFICAÇÃO & DENSIDADE [kg/L] & TEOR DE SÓLIDOS [\%] & pH & DOSAGEM RECOMENDADA \\
\hline Fabricante A & 1,050 a 1,080 & NA & 5 a 7 & $0,2 \%$ a $2,0 \%$ \\
\hline Fabricante B & 1,067 a 1,107 & 28,5 a 31,5 & 5 a 7 & $0,2 \%$ a $1,0 \%$ \\
\hline Fabricante C & 1,080 a 1,120 & NA & 5 a 7 & $0,3 \%$ a $2,0 \%$ \\
\hline
\end{tabular}

NA - Não informado pelo fabricante.

\section{MÉTODOS}

\subsection{Preparo das amostras}

O método de mistura foi realizado de acordo com a norma ASTM C1738 [32] para todos os procedimentos de caracterização. Um resumo dos materiais, teores e condições de ensaio é apresentado no Quadro 1.

Quadro 1: Resumo das variáveis de estudo.

\begin{tabular}{|c|c|c|c|}
\hline CIMENTOS & TEMPERATURAS & TEORES DE SP [\%] & ADITIVOS \\
\hline \multirow{3}{*}{ CP IV } & \multirow{2}{*}{$25^{\circ} \mathrm{C}$} & 0,40 & \multirow{2}{*}{ Fabricante A } \\
\hline & & 0,55 & \\
\hline & \multirow[t]{2}{*}{$35^{\circ} \mathrm{C}$} & 0,70 & \multirow[t]{2}{*}{ Fabricante B } \\
\hline \multirow{2}{*}{ CP V ARI } & & 0,85 & \\
\hline & $45^{\circ} \mathrm{C}$ & 1,00 & Fabricante $\mathrm{C}$ \\
\hline
\end{tabular}

As matérias-primas para a mistura foram aquecidas de acordo com as temperaturas estipuladas $(25,35 \mathrm{e}$ $45^{\circ} \mathrm{C}$ ) e a quantidade de aditivo foi subtraída do teor total de água da mistura. A composição das amostras avaliadas é apresentada na Tabela 4.

\subsection{Mini-abatimento}

Para estudar o efeito do teor dos superplastificantes nas propriedades reológicas das pastas de cimento, inicialmente foi realizado o ensaio de mini-abatimento, de acordo com o indicado por KANTRO [33] (Figura 1). Neste, o espalhamento da amostra é mensurado nos tempos de 0, 15 e 30 minutos após a mistura (Figura 2). A variação do espalhamento ao longo do ensaio permite avaliar a perda de abertura ao longo do tempo. $\mathrm{O}$ ensaio de mini-abatimento é aplicado em estudos de pastas aditivadas [34, 35] e a variação do espalhamento ao longo do ensaio permite avaliar a perda de abertura ao longo do tempo.

O teor de SP para o qual se obtém o espalhamento máximo é definido como "ponto de saturação" ou "teor ótimo". Para dosagens acima deste valor, o poder dispersante do SP varia minimamente e tende a reduzir. De acordo com PUERTAS et al. [37], tal efeito se relaciona à adsorção do policarboxilato ao grão de cimento, uma vez que a molécula interage principalmente com os aluminatos presentes no aglomerante. Para um aumento do espalhamento seria necessário um correspondente aumento no teor do cimento. 
Tabela 4: Composição das amostras.

\begin{tabular}{|c|c|c|c|c|c|c|}
\hline AMOSTRA & CP IV [g] & CP V ARI [g] & ÁGUA [g] & SP A [g] & SP B [g] & SP C [g] \\
\hline 01 & 500 & & 148,00 & 2,00 & & \\
\hline 02 & 500 & & 147,25 & 2,75 & & \\
\hline 03 & 500 & & 146,50 & 3,50 & & \\
\hline 04 & 500 & & 145,75 & 4,25 & & \\
\hline 05 & 500 & & 145,00 & 5,00 & & \\
\hline 06 & 500 & & 148,00 & & 2,00 & \\
\hline 07 & 500 & & 147,25 & & 2,75 & \\
\hline 08 & 500 & & 146,50 & & 3,50 & \\
\hline 09 & 500 & & 145,75 & & 4,25 & \\
\hline 10 & 500 & & 145,00 & & 5,00 & \\
\hline 11 & 500 & & 148,00 & & & 2,00 \\
\hline 12 & 500 & & 147,25 & & & 2,75 \\
\hline 13 & 500 & & 146,50 & & & 3,50 \\
\hline 14 & 500 & & 145,75 & & & 4,25 \\
\hline 15 & 500 & & 145,00 & & & 5,00 \\
\hline 16 & & 500 & 148,00 & 2,00 & & \\
\hline 17 & & 500 & 147,25 & 2,75 & & \\
\hline 18 & & 500 & 146,50 & 3,50 & & \\
\hline 19 & & 500 & 145,75 & 4,25 & & \\
\hline 20 & & 500 & 145,00 & 5,00 & & \\
\hline 21 & & 500 & 148,00 & & 2,00 & \\
\hline 22 & & 500 & 147,25 & & 2,75 & \\
\hline 23 & & 500 & 146,50 & & 3,50 & \\
\hline 24 & & 500 & 145,75 & & 4,25 & \\
\hline 25 & & 500 & 145,00 & & 5,00 & \\
\hline 26 & & 500 & 148,00 & & & 2,00 \\
\hline 27 & & 500 & 147,25 & & & 2,75 \\
\hline 28 & & 500 & 146,50 & & & 3,50 \\
\hline 29 & & 500 & 145,75 & & & 4,25 \\
\hline 30 & & 500 & 145,00 & & & 5,00 \\
\hline
\end{tabular}

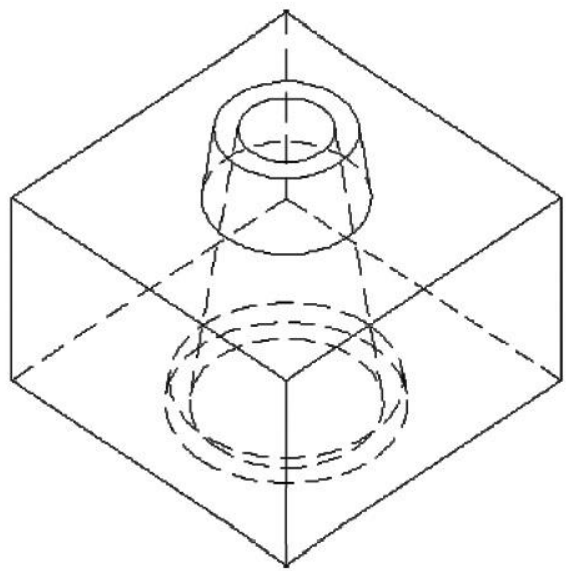

a) Perspectiva

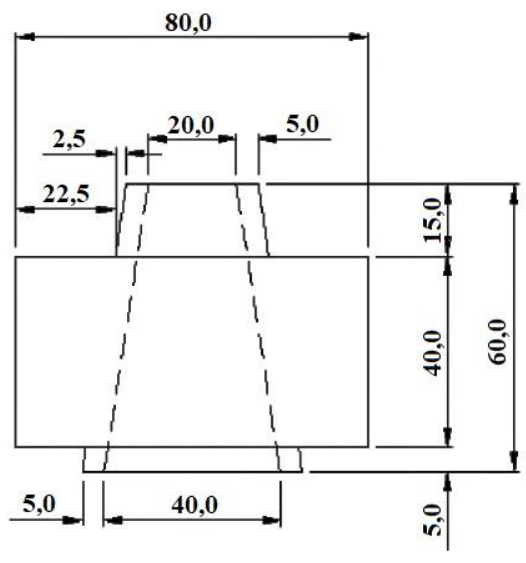

b) Vista lateral

Figura 1: Dimensões do molde tronco-cônico para ensaio de mini-abatimento [36]. 


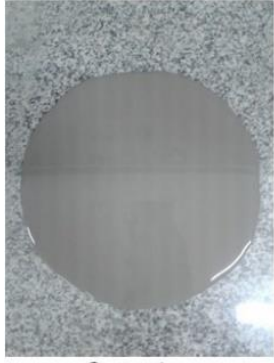

$0 \mathrm{~min}$

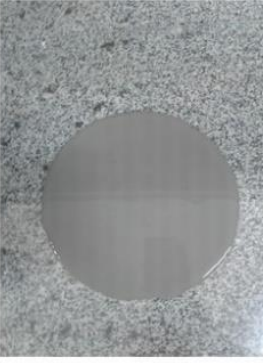

$15 \mathrm{~min}$

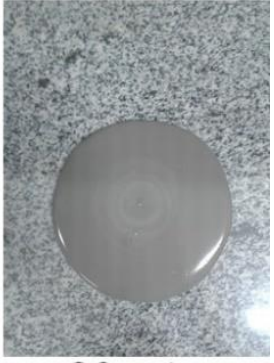

$30 \mathrm{~min}$

Figura 2: Exemplo de evolução do espalhamento com o tempo para pasta aditivada com superplastificante.

\subsection{Reometria Rotacional}

Para analisar os efeitos da temperatura nos parâmetros reológicos das pastas cimentícias aditivadas, foram também realizados ensaios no reômetro, conhecido como viscosímetro, Brookfield modelo RS Plus de cilindros coaxiais, com apoio do banho termostatizado. O misturador interno foi do tipo Bob Spindle CC3-25 e a geometria das peças do reômetro é apresentada na Figura 3. A rotina de ensaio e determinação dos parâmetros de tensão e viscosidade foram realizadas em concordância com a norma ASTM C1749 [38].

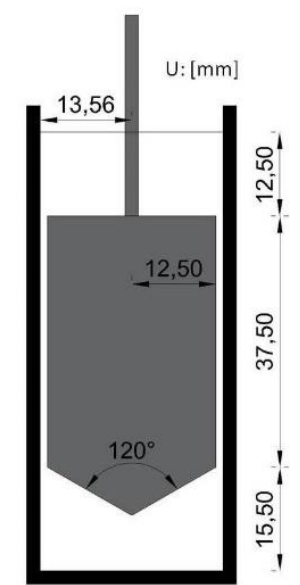

Figura 3: Vista lateral da geometria das peças do reômetro.

O perfil de solicitação aplicado (Figura 4) foi escolhido de acordo com a norma ASTM C1749 [38]. Visando relacionar os parâmetros reológicos obtidos na reometria rotacional com os dados encontrados a partir dos ensaios de mini-abatimento, optou-se por realizar três ciclos de aceleração/desaceleração. Observa-se que os ciclos aplicados na reometria coincidem com os tempos das medidas do espalhamento.

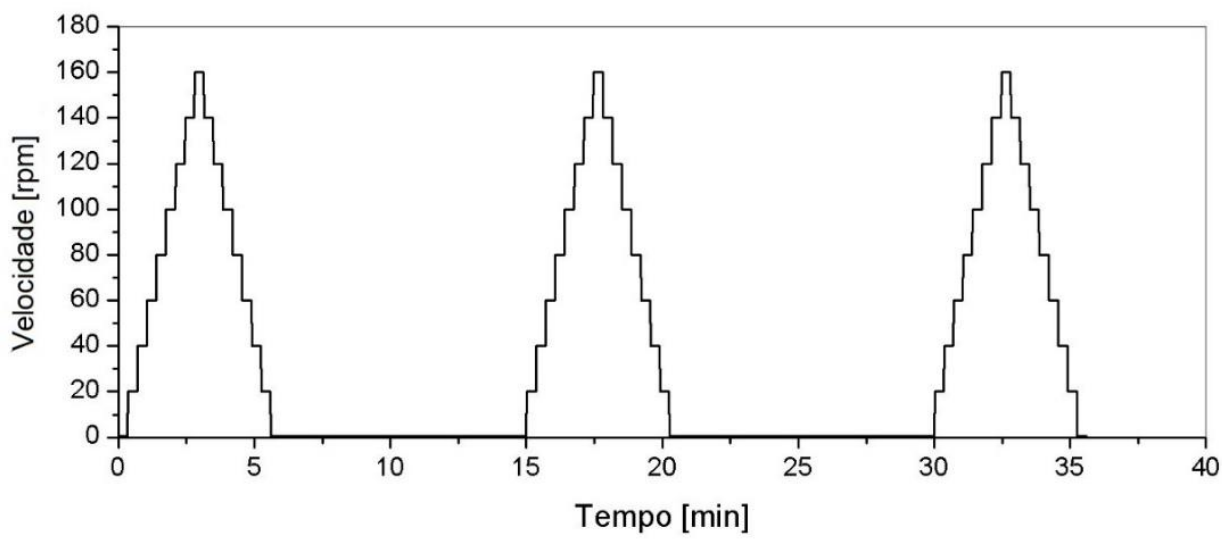

Figura 4: Perfil de solicitação aplicado. 
A tensão de escoamento e a viscosidade plástica para cada fluido foram estimadas a partir da aplicação dos modelos de Bingham e de Herschel-Bulkley nas curvas descendentes de cada ciclo da reometria rotacional. De acordo com BANFILL [39], em suspensões concentradas de sólidos em líquidos, tais como os sistemas cimentícios, a proximidade das partículas dá origem a interações, cuja força depende da forma das partículas, da sua distribuição granulométrica, concentração, tipo de superfície e da composição do líquido. Deste modo, esse material concentrado, que tem forças que atuam entre as partículas sólidas, obedece ao modelo Bingham. Este, por sua vez é vastamente aplicado em estudos de pastas cimentícias aditivadas [40-42], além de ser o recomendado pela ASTM C1749 [38] e pode ser descrito pela Equação 1.

$$
\tau=\tau_{0}+\mu \cdot \dot{\gamma}
$$

Onde:

$\tau:$ Tensão de Cisalhamento

$\tau_{0} \leftleftarrows$ Tensão de Escoamento

$\mu$ : Viscosidade

$\dot{\gamma}^{\star}$ Taxa de Deformação

Para suspensões altamente fluidas o modelo de Bingham por vezes estima tensões de escoamento negativas em razão das reduzidas viscosidades iniciais e aproximações da regressão linear aplicada nas curvas de fluxo [27, 43]. A tentativa de um ajuste linear direciona a um coeficiente linear (tensão de escoamento) negativo, no entanto, esse não reflete o comportamento real do material e é um dado incoerente fisicamente. Por outro lado, o modelo de Bingham permite determinar a viscosidade plástica do material, a qual corresponde à inclinação da curva de fluxo. Há vertentes do estudo dos parâmetros reológicos de materiais cimentícios que consideram válidos os valores de viscosidade plástica mesmo quando obtidos em ajustes com tensão de escoamento negativa, desprezando-se apenas o valor desta última variável. Tal abordagem será aplicada na presente pesquisa e pode ser observada nos trabalhos de JAYASREE e GETTU [44], SENFF et al. [45], SATHYAN et al. [46] e ROBERT et al. [47].

O comportamento reológico do fluido também pode ser descrito pelo modelo de Herschel-Bulkley, representado pela Equação 2. Além da tensão de escoamento, o modelo estima o índice de comportamento do fluido (n), parâmetro que classifica os fluidos como dilatante $(n>1)$ ou pseudoplástico $(n<1)$ [48]. O índice de consistência (K) em geral só pode ser utilizado para comparação entre amostras com comportamentos semelhantes, pois sua unidade de medida é dada em Pa.s ${ }^{\mathrm{n}}$ de modo que para cada pasta a unidade varia em função do índice de comportamento do fluido (n) obtido [44].

$$
\tau=\tau_{0}+K \cdot \dot{\gamma}^{n}
$$

Onde:

$\tau$ : Tensão de Cisalhamento

$\tau_{0} \approx$ Tensão de Escoamento

$\mathrm{K}$ : Índice de Consistência

$\dot{\gamma} \leftleftarrows$ Taxa de Deformação

$\mathrm{n}$ : Índice de comportamento do fluido

Ao aplicar uma taxa de cisalhamento partindo do zero até um determinado valor e em seguida retornando à taxa inicial, é possível determinar um indicador da tixotropia do fluido. Esta pode ser descrita como a energia necessária para promover o fluxo do material [49-51]. A combinação entre as curvas de fluxo de aceleração e desaceleração é chamada ciclo de histerese e sua área corresponde ao indicador de tixotropia. A tixotropia é diretamente proporcional à destruição estrutural ocorrida no material, bem como à mudança nas suas propriedades reológicas quando submetido a um ciclo de cisalhamento. Um exemplo das curvas de fluxo de uma pasta cimentícia utilizadas para cálculo das áreas de histerese é apresentado na Figura 5. Tal parâmetro foi calculado a partir de um método matemático aplicando a integral entre as curvas de aceleração e desaceleração para cada ciclo. 


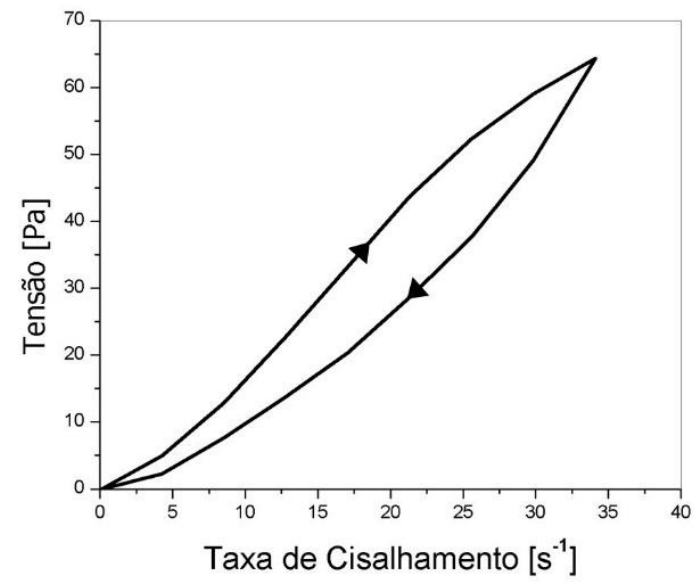

Figura 5: Curvas de fluxo de uma pasta cimentícia.

\section{RESULTADOS E DISCUSSÕES}

A Figura 6(a-i) apresenta os espalhamentos obtidos nos ensaios de mini-abatimento realizados com pastas de cimento Portland tipo IV variando de acordo com o tempo e teor de aditivo.

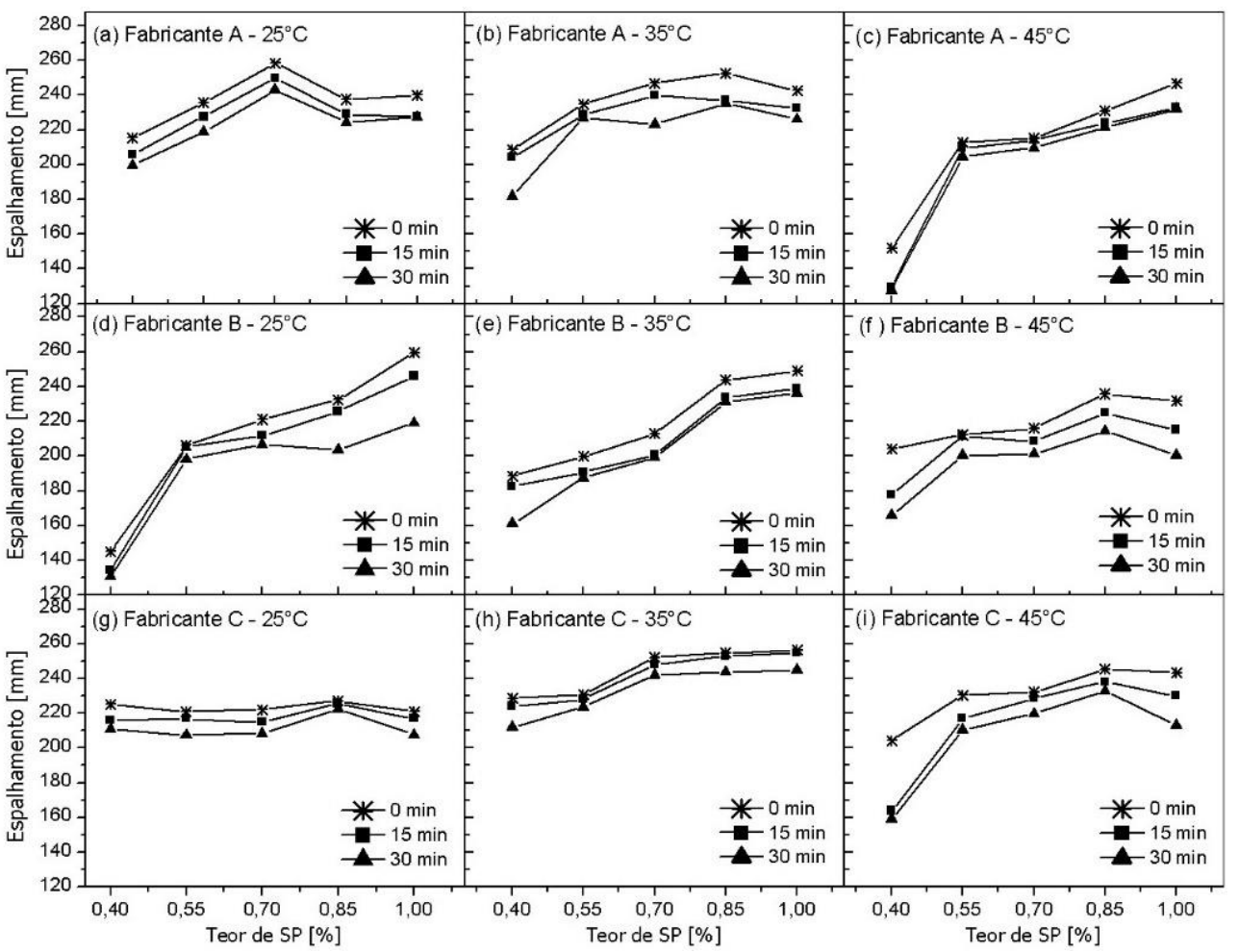

Figura 6: Espalhamento das pastas de cimento Portland tipo IV em função do teor de SP e do tempo para diferentes temperaturas de ensaio.

Os resultados de mini-abatimento das pastas com cimento Portland tipo V ARI são apresentados na Figura $7(\mathrm{a}-\mathrm{i})$. 


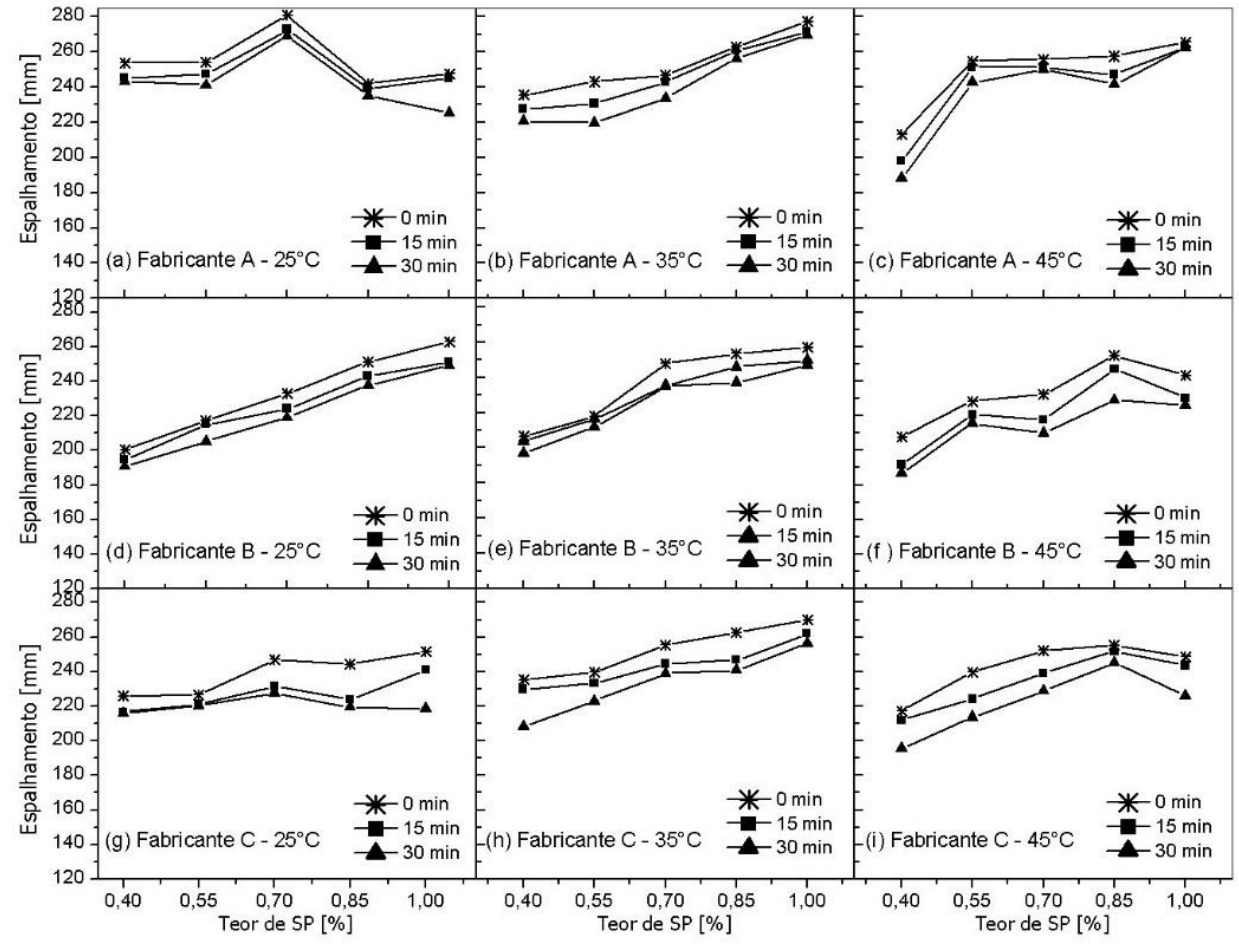

Figura 7: Espalhamento das pastas de cimento Portland tipo V ARI em função do teor de SP e do tempo para diferentes temperaturas de ensaio.

Aplicando o modelo reológico de Bingham, estimam-se as viscosidades plásticas das pastas de cimento Portland tipo IV que são apresentadas na Figura 8(a-i). A Figura 9(a-i) apresenta as viscosidades plásticas das pastas de cimento Portland tipo V ARI.

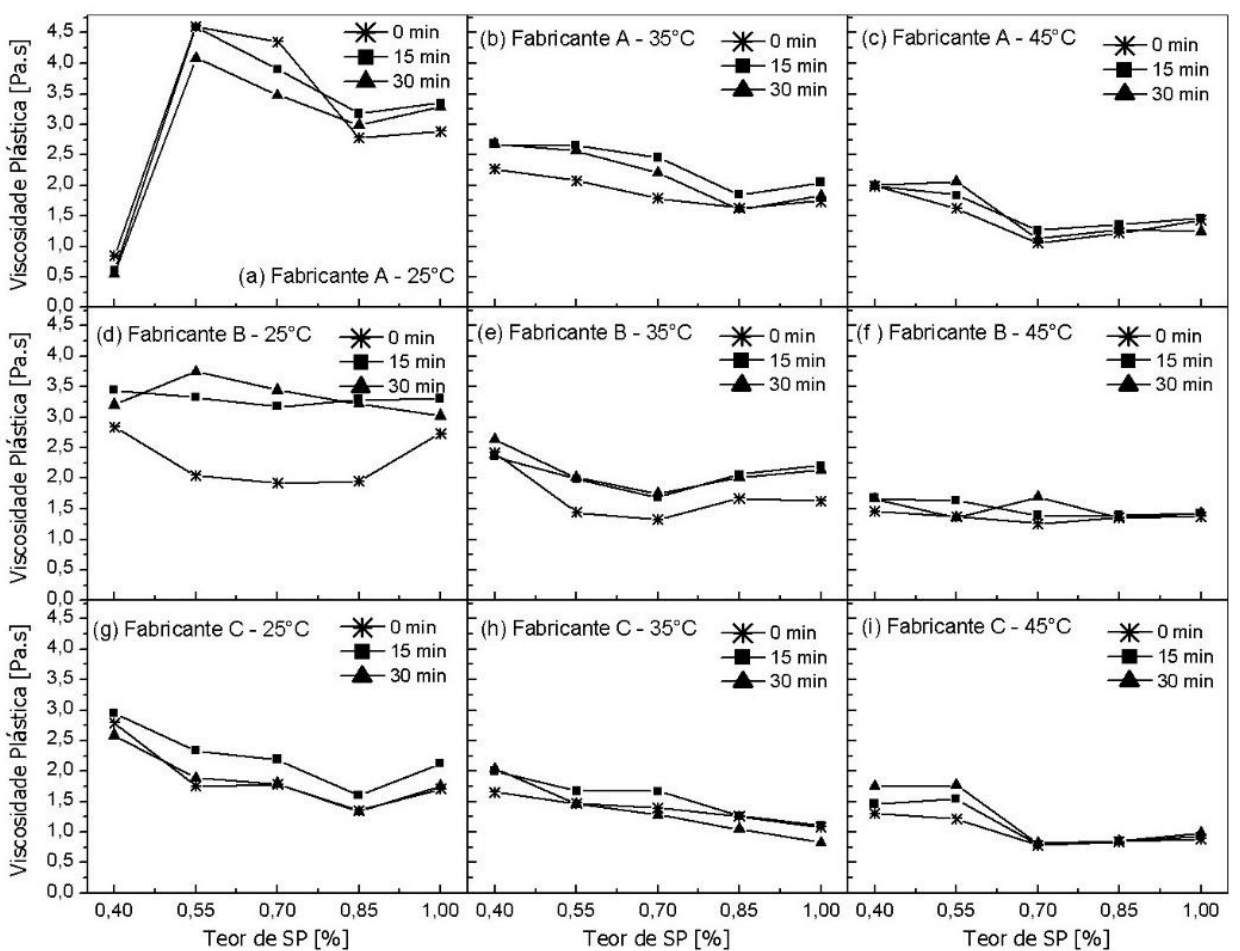

Figura 8: Viscosidade plástica das pastas de cimento Portland tipo IV em função do teor de SP e do tempo para diferentes temperaturas de ensaio. 


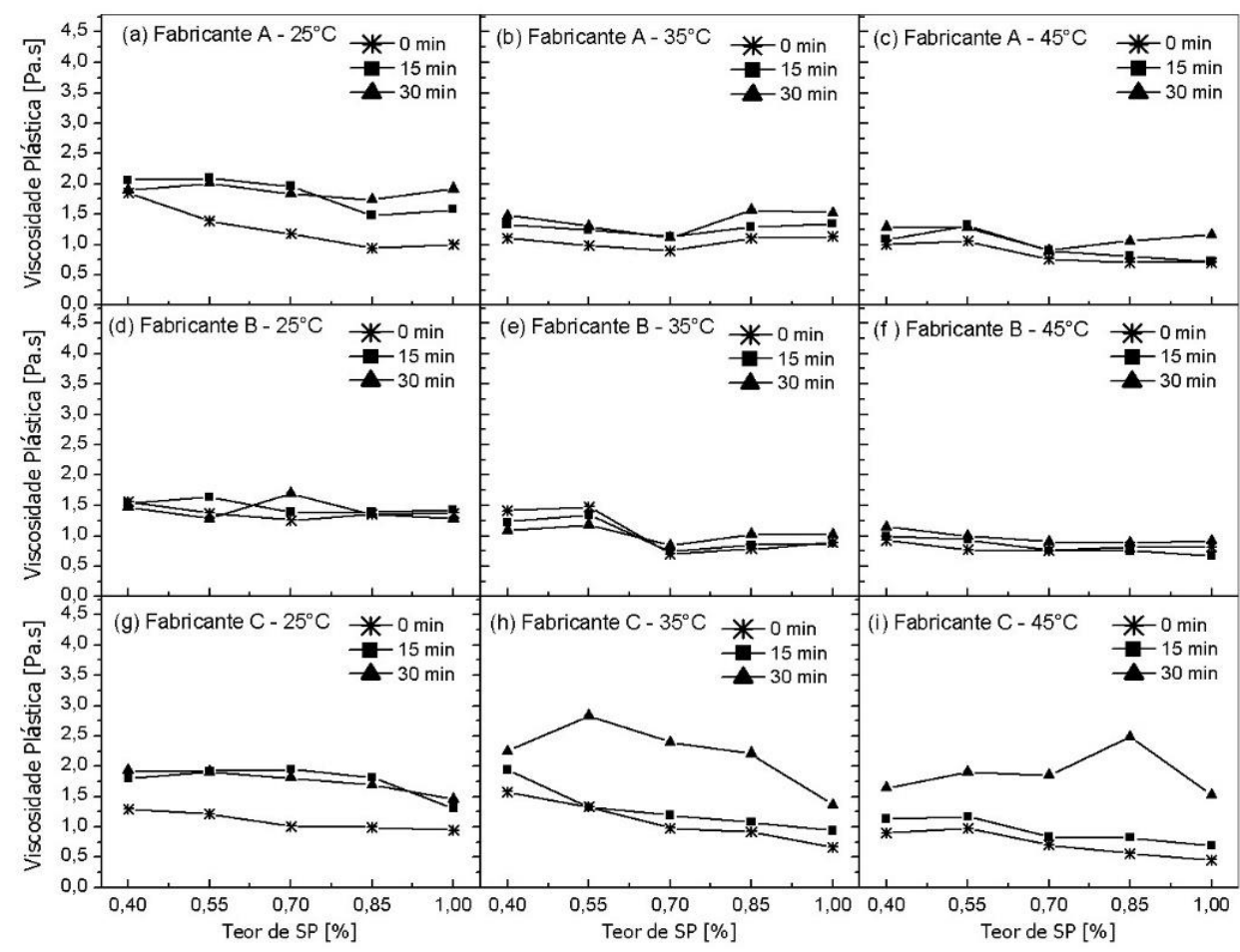

Figura 9: Viscosidade plástica das pastas de cimento Portland tipo V ARI em função do teor de SP e do tempo para diferentes temperaturas de ensaio.

Uma vez que o modelo de Bingham forneceu tensão de escoamento negativa para algumas composições, tal parâmetro reológico foi estimado através do modelo de Herschel-Bulkley e seus valores são apresentados nas Figuras 10(a-i) e 12(a-i).

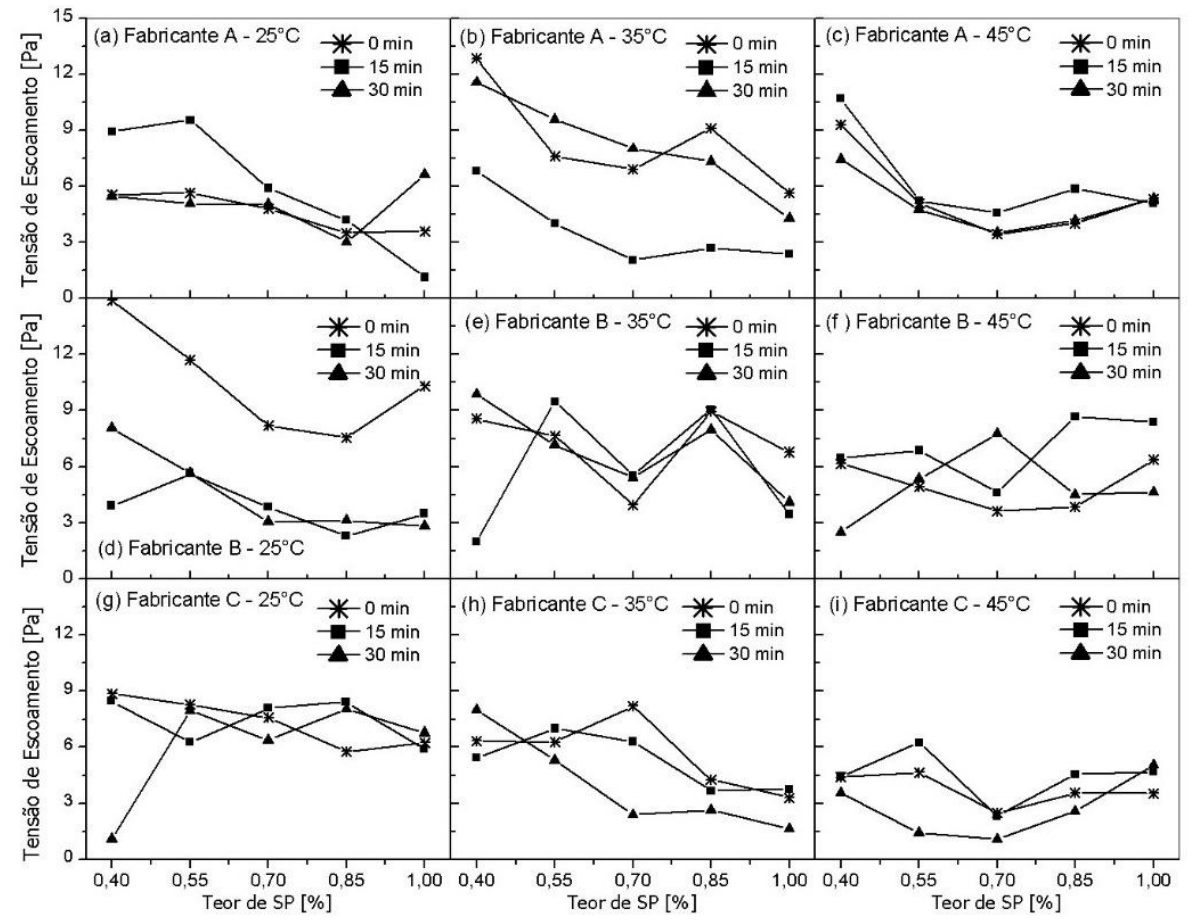

Figura 10: Tensões de escoamento das pastas de cimento Portland tipo IV em função do teor de SP e do tempo para diferentes temperaturas de ensaio.

A Figura 11(a-i) apresenta as tensões de escoamento das pastas de CP V ARI. 


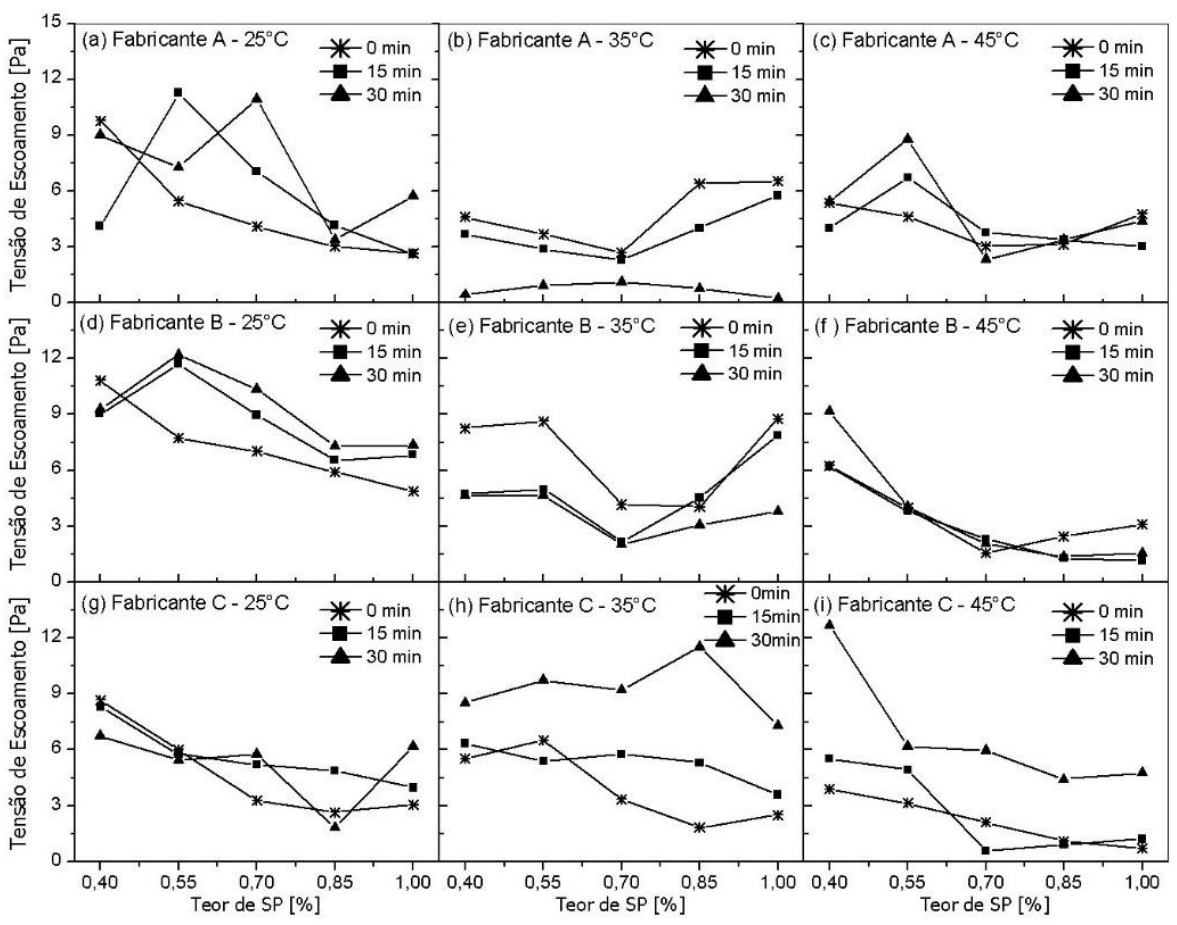

Figura 11: Tensões de escoamento das pastas de cimento Portland tipo V ARI em função do teor de SP e do tempo para diferentes temperaturas de ensaio.

Os valores de índice de comportamento do fluido obtidos pelo modelo de Herschel-Bulkley são apresentados na tabela 5 .

Tabela 5: Índices de comportamento (n) das pastas pelo modelo de Herschel-Bulkley (0 min).

\begin{tabular}{|c|c|c|c|c|c|c|c|}
\hline ADITIVO & TEOR [\%] & CPIV $25^{\circ} \mathrm{C}$ & CPIV. $35^{\circ} \mathrm{C}$ & CPIV. $45^{\circ} \mathrm{C}$ & CPV $.25^{\circ} \mathrm{C}$ & CPV $.35^{\circ} \mathrm{C}$ & CPV. $45^{\circ} \mathrm{C}$ \\
\hline \multirow{5}{*}{ Fabricante A } & 0,40 & 1,891 & 2,467 & 2,391 & 2,129 & 1,851 & 1,381 \\
\hline & 0,55 & 1,835 & 2,263 & 2,021 & 2,038 & 2,033 & 1,369 \\
\hline & 0,70 & 1,982 & 2,144 & 2,219 & 2,056 & 1,948 & 1,754 \\
\hline & 0,85 & 2,702 & 2,378 & 2,129 & 1,756 & 2,053 & 1,732 \\
\hline & 1,00 & 2,614 & 2,296 & 2,403 & 1,754 & 1,945 & 1,835 \\
\hline \multirow{5}{*}{ Fabricante B } & 0,40 & 2,498 & 2,779 & 1,984 & 2,072 & 2,217 & 1,718 \\
\hline & 0,55 & 2,177 & 2,086 & 1,891 & 2,191 & 2,048 & 1,824 \\
\hline & 0,70 & 2,138 & 2,091 & 1,971 & 1,641 & 1,749 & 1,691 \\
\hline & 0,85 & 2,099 & 2,132 & 2,119 & 1,677 & 1,793 & 1,660 \\
\hline & 1,00 & 2,167 & 2,273 & 2,280 & 1,657 & 1,629 & 1,790 \\
\hline \multirow{5}{*}{ Fabricante $\mathrm{C}$} & 0,40 & 2,395 & 2,575 & 2,358 & 2,336 & 2,088 & 1,923 \\
\hline & 0,55 & 2,619 & 2,331 & 2,153 & 2,044 & 2,196 & 1,846 \\
\hline & 0,70 & 2,455 & 1,947 & 2,455 & 1,952 & 1,997 & 1,898 \\
\hline & 0,85 & 2,529 & 2,091 & 2,165 & 1,896 & 1,973 & 1,830 \\
\hline & 1,00 & 2,246 & 2,044 & 2,081 & 1,998 & 1,805 & 1,762 \\
\hline
\end{tabular}

O parâmetro de índice de consistência não pôde ser utilizado para comparação entre as pastas, pois sua unidade de medida é dada em Pa.s ${ }^{\mathrm{n}}$ de modo que para cada pasta a unidade varia em função do índice de comportamento do fluido (n) obtido. $\mathrm{O}$ coeficiente de variação do parâmetro $\mathrm{n}$ para cada grupo de amostras (classificadas por fabricante do aditivo) indicou valor acima de $5 \%$, o que poderia garantir maior confiabilidade à comparação entre os valores de K para cada grupo de amostras. Sendo de aproximadamente 11, 15 e $14 \%$ para os SPs dos fabricantes A, B e C, respectivamente. 
Calculando-se a área confinada entre as curvas de fluxo para cada amostra analisada, obtém-se um parâmetro diretamente associado à energia necessária para destruição estrutural ocorrida durante a reometria. Os indicadores de tixotropia são apresentados na Figura 12(a-i).

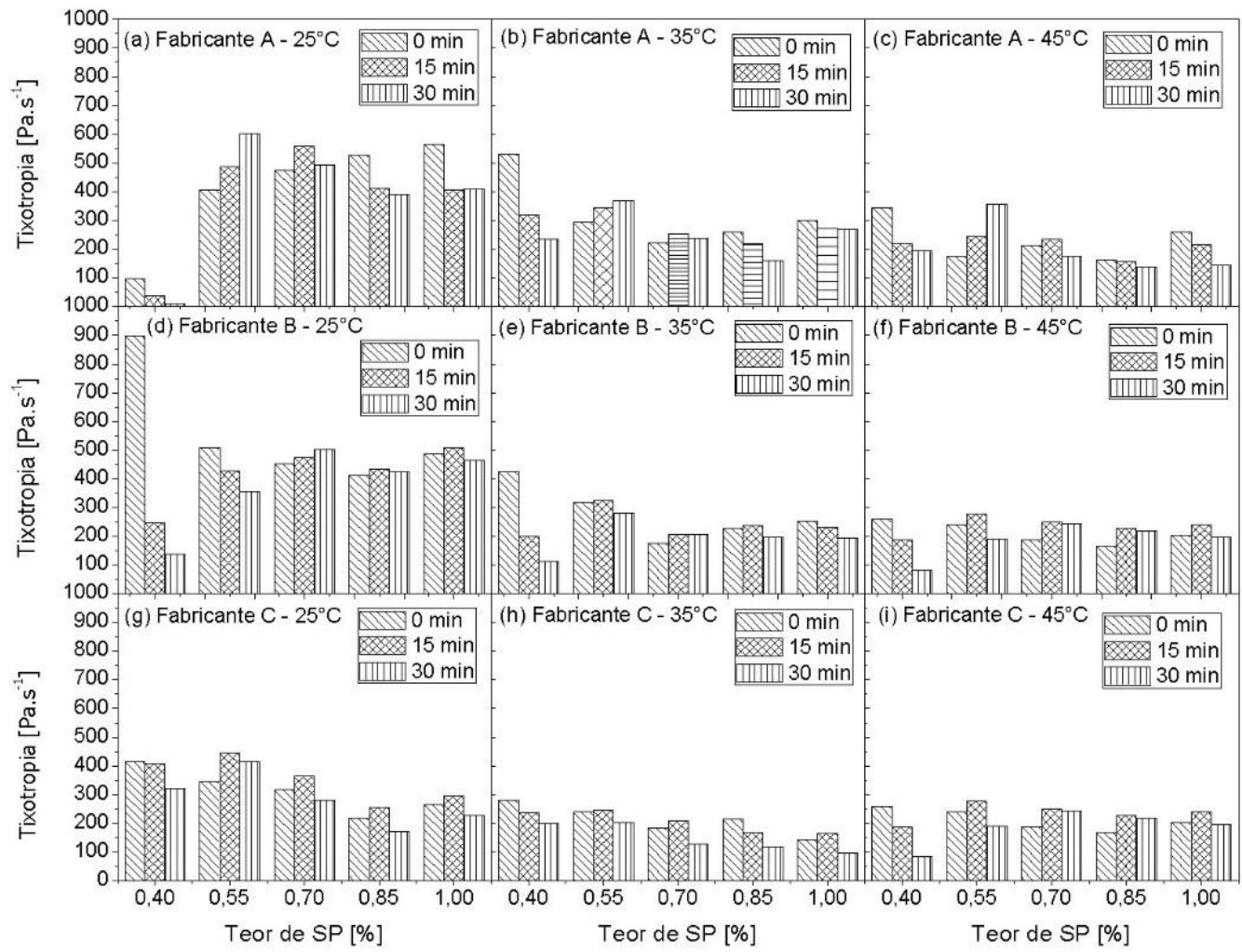

Figura 12: Indicadores de tixotropia das pastas de cimento Portland tipo IV em função do teor de SP e do tempo para diferentes temperaturas de ensaio.

A Figura 13(a-i) apresenta os indicadores de tixotropia das pastas de CP V ARI. 


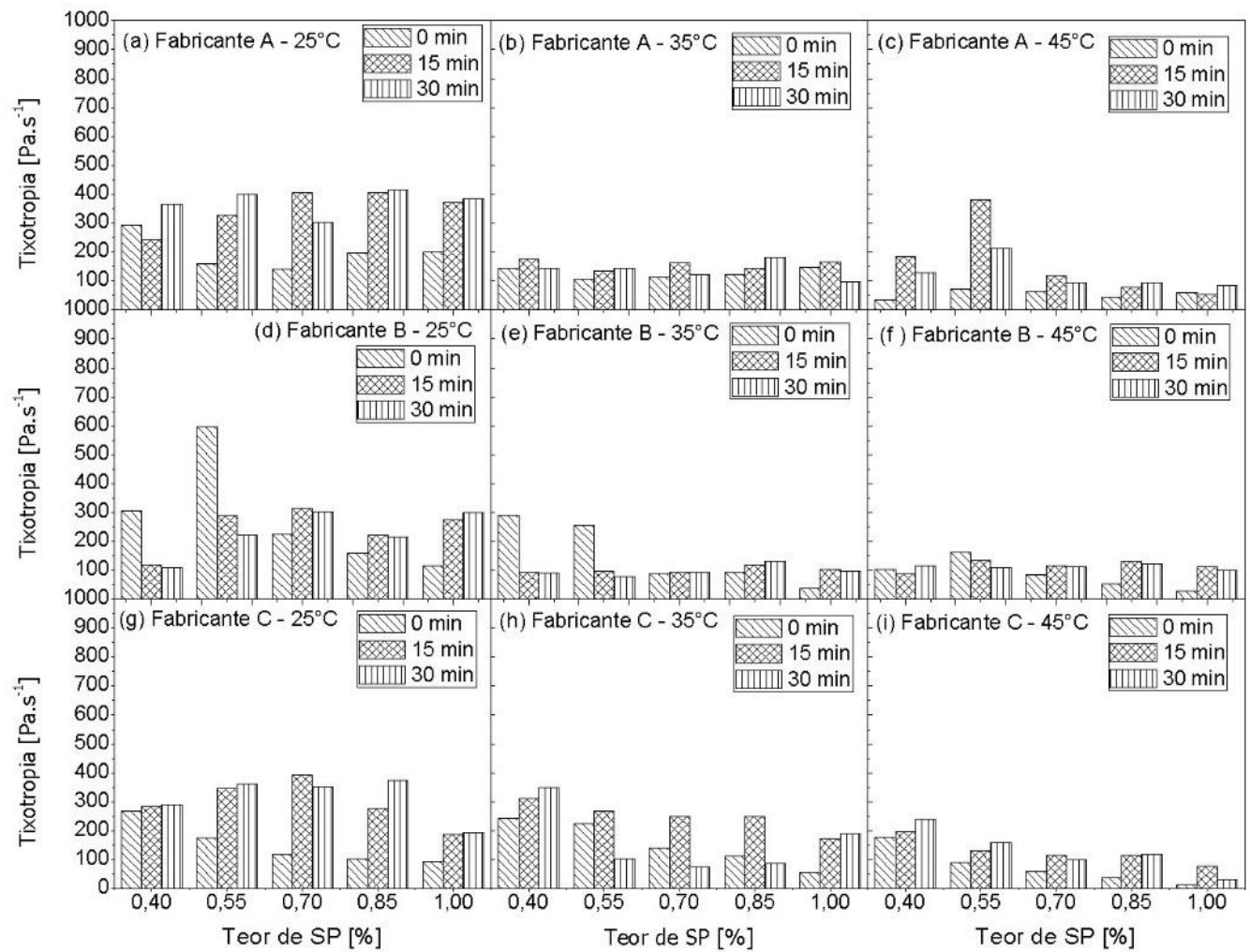

Figura 13: Indicadores de tixotropia das pastas de cimento Portland tipo V ARI em função do teor de SP e do tempo para diferentes temperaturas de ensaio.

\subsection{Discussão}

\subsubsection{Influência da temperatura}

As amostras com o aditivo do fabricante A apresentaram plasticidade superior mesmo com o aumento da temperatura. Este comportamento pode ser justificado por se tratar de um aditivo com função de abertura/espalhamento. Os teores de saturação foram de $0,70 \%$ para a amostra de $45{ }^{\circ} \mathrm{C}$ e $1,00 \%$ para as misturas de $35{ }^{\circ} \mathrm{C}$ e $25{ }^{\circ} \mathrm{C}$. Os espalhamentos das composições com o aditivo do fabricante B variaram minimamente para todas as temperaturas, não apresentando um padrão específico de variação, desempenho de acordo com a sua função que é de manutenção. As pastas cimentícias aditivadas com o produto do fabricante $\mathrm{C}$ indicaram espalhamento superior aos $25^{\circ} \mathrm{C}$ e reduzida variação para as avaliações aos $35^{\circ} \mathrm{C}$ e $45{ }^{\circ} \mathrm{C}$. Os teores de saturação foram de $1,00 \%$ para as misturas de $25{ }^{\circ} \mathrm{C}$ e $35^{\circ} \mathrm{C}$ e $0,85 \%$ para as amostras de $45^{\circ} \mathrm{C}$ indicando que a temperatura causa mudanças consideráveis no ponto de saturação de superplastificante. De um modo geral, a temperatura de $45^{\circ} \mathrm{C}$ ocasionou uma considerável perda do espalhamento com o tempo. Conforme reportado por ZHANG et al. [24], pastas cimentícias com alto teor de superplastificante são menos suscetíveis à redução do seu desempenho frente a variações de temperatura. O aumento da temperatura em geral reduziu as tensões de escoamento e as viscosidades plásticas das pastas cimentícias. Comportamento semelhante ao que foi identificado nos estudos de FERNÀNDEZ-ALTABLE e CASANOVA [52] e PETIT et al. [22]. No entanto, a variação das tensões de escoamento para as composições com o aditivo do fabricante A não apresentou padrão específico.

Calculando as áreas confinadas entre as curvas de aceleração e desaceleração para cada pasta analisada, identificam-se indicadores de tixotropia. Estes são diretamente proporcionais à diferença entre a energias necessária para promover a mistura durante os trechos de aceleração e desaceleração da taxa de cisalhamento. $\mathrm{O}$ incremento na temperatura reduziu a tixotropia nos ciclos de cisalhamento das pastas e o mesmo comportamento foi observado por FERNÀNDEZ-ALTABLE e CASANOVA [52]. Por ser um aditivo de alto desempenho desenvolvido especificamente para a função de abertura, o produto do fabricante A proporcionou espalhamentos superiores mesmo com o aumento da temperatura. Com relação ao índice de comportamento do fluido, observa-se uma redução da característica pseudoplástica das pastas com o aumento da temperatura.

$\mathrm{O}$ incremento da temperatura atuou reduzindo as tensões de escoamento, viscosidades plásticas e tixotropia das pastas cimentícias. A temperatura mais elevada ocasionou a redução da capacidade de conservação da plasticidade ao longo do tempo. 


\subsubsection{Influência do tipo de cimento}

$\mathrm{O}$ aglomerante de maior pureza (CP V ARI) promoveu misturas com menores viscosidades plásticas, uma vez que a resistência ao fluxo está diretamente associada à dimensão das partículas em suspensão, bem como ao atrito entre as mesmas [53]. As amostras aditivadas com os produtos dos fabricantes A apresentaram um aumento do teor de saturação ao mudar do CP IV para o CPV ARI aos $35^{\circ} \mathrm{C}$. Isso se relaciona à adsorção do policarboxilato ao grão de cimento, devido ao fato de que a molécula interage principalmente nos aluminatos do cimento, e uma vez que se processem adições (cinzas volantes, sílica ativa, pozolanas, etc.), a proporção de grãos de cimento na mistura é diminuída e, deste modo, o efeito dispersante do superplastificante é reduzido [37, 54]. Por outro lado, as pastas com aditivo do fabricante $C$ mantiveram seus pontos de saturação mesmo após a troca do tipo de cimento.

As formulações com CP IV apresentaram elevadas tensões de escoamento, viscosidades e tixotropias, quando comparadas às pastas de CP V ARI. Um comportamento semelhante foi identificado por NANTHAGOPALAN et al. [55] ao comparar os parâmetros reológicos de pastas cimentícias com adição de cinza volante e sílica ativa. Tal desempenho pode ser justificado pela limitada disponibilidade de aluminatos sobre os quais ocorre a adsorção do aditivo. Além deste fator, estudos realizados em pastas cimentícias de diferentes composições químicas indicam que os fatores preponderantes no desempenho reológico são a relação água/aglomerante e a finura do cimento [56]. A finura do cimento é uma propriedade relacionada ao tamanho dos grãos do material e governa a velocidade da reação de hidratação do mesmo, bem como a reologia de suas pastas. De acordo com LARRARD e SEDRAN [57], a tensão de escoamento resulta do atrito intergranular durante o cisalhamento da matriz, enquanto a viscosidade plástica depende fundamentalmente do escoamento da água nos poros do sistema granular. $\mathrm{O}$ aumento do atrito interpartícula do cimento influencia nas propriedades reológicas de pastas cimentícias ocasionando um incremento na tensão de escoamento e na viscosidade plástica. As pastas de CPIV apresentaram índice de comportamento médio maiores quando comparadas às misturas com CP V ARI, apresentando uma variação de cerca de $15 \%$.

As formulações com o aglomerante de maior pureza apresentaram tensões de escoamento, viscosidades e tixotropias inferiores. Este comportamento está relacionado à adsorção do policarboxilato ao grão de cimento em função do elevado teor de aluminatos na composição e teve como consequência um incremento nos teores de saturação dos aditivos.

\subsubsection{Influência do aditivo}

As composições com o aditivo do fabricante A apresentaram elevada plasticidade para todas as temperaturas aplicadas. O produto do fabricante $\mathrm{B}$, embora inicialmente tenha promovido espalhamentos inferiores, possui aprimorada capacidade de conservação da plasticidade ao longo do tempo. Apresentando um desempenho final superior quando comparado com os outros aditivos. SCHEEREN et al. [58] verificaram o mesmo comportamento ao avaliar as interações de uma pasta cimentícia com dois tipos de superplastificantes à base policarboxilato com função de abertura (elevada fluidez) e manutenção (prolongado tempo de ação). Dentro desta classificação, o aditivo do fabricante A poderia ser classificado como de abertura, enquanto que o do fabricante $\mathrm{B}$ apresenta a função de manutenção. Observa-se que os valores de espalhamento aumentam à medida que se incrementa o teor de superplastificante até ponto de saturação e decrescem ao longo do tempo de ensaio (Figura 6a). Os dados reológicos indicam que a viscosidade plástica decresce ao passo que o teor de aditivo aumenta até a dosagem de saturação e apresenta valores superiores para o fabricante B. As viscosidades plásticas são mínimas para as composições produzidas com o aditivo do fabricante C (Figura 14). Comportamento semelhante foi identificado por ERZENGIN et al. [27] LI et al. [59] e em argamassas e por OUALIT et al. [60] na avaliação de pastas cimentícias. 


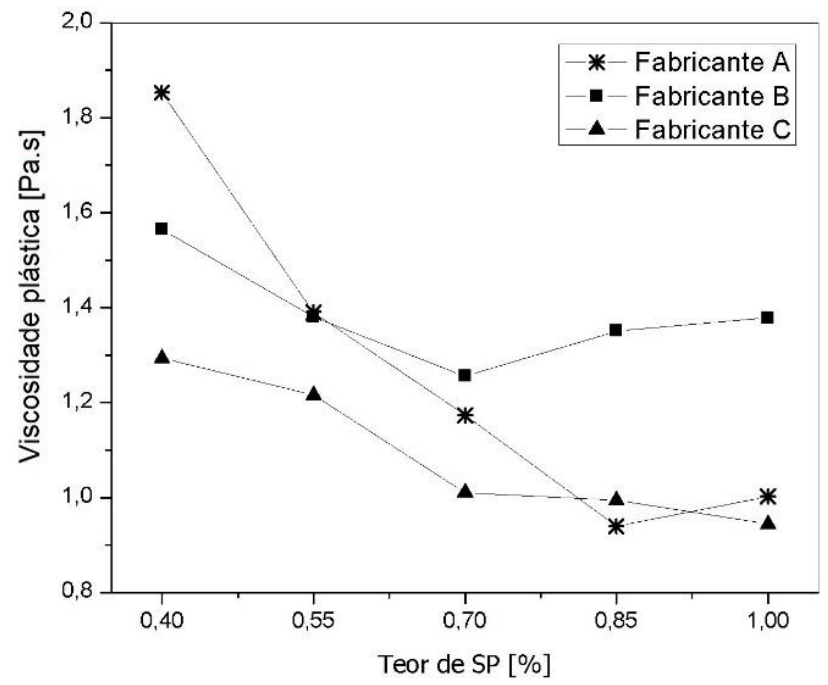

Figura 14: Viscosidades plásticas das pastas de CP V ARI a $25^{\circ} \mathrm{C}$ após o primeiro ciclo de cisalhamento (0 min).

As amostras apresentaram uma tendência de redução da tixotropia com um aumento do teor de aditivo até o seu teor ótimo, como pode ser observado no exemplo da Figura 15. Tanto a viscosidade quanto a tixotropia incrementaram ao longo do tempo de ensaio. As tensões de escoamento foram superiores para as pastas aditivadas com o produto do fabricante $\mathrm{B}$, ao passo que os valores foram mínimos para as composições com o aditivo do fabricante A, como pode ser observado no exemplo da Figura 16.

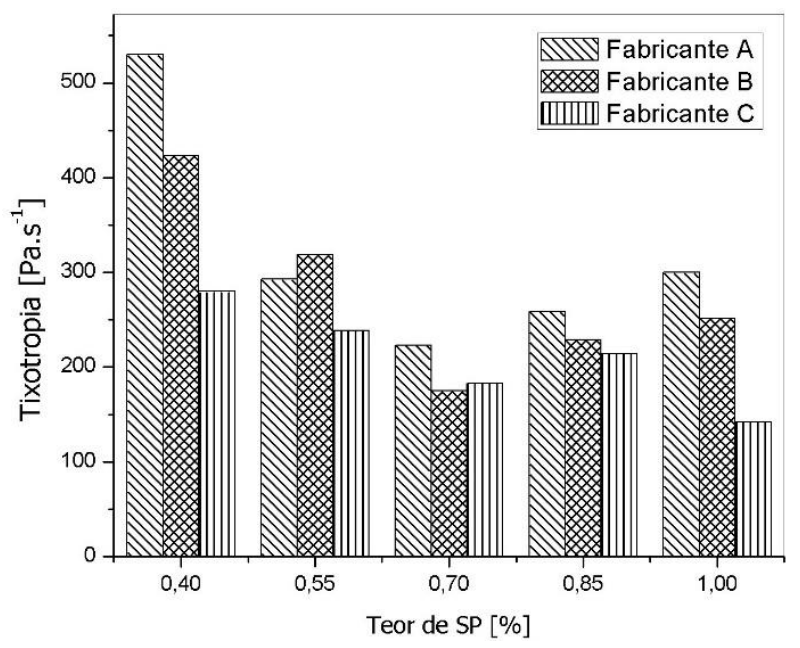

Figura 15: Tixotropia das pastas de CP IV a $35^{\circ} \mathrm{C}$ após o primeiro ciclo de cisalhamento ( 0 min). 


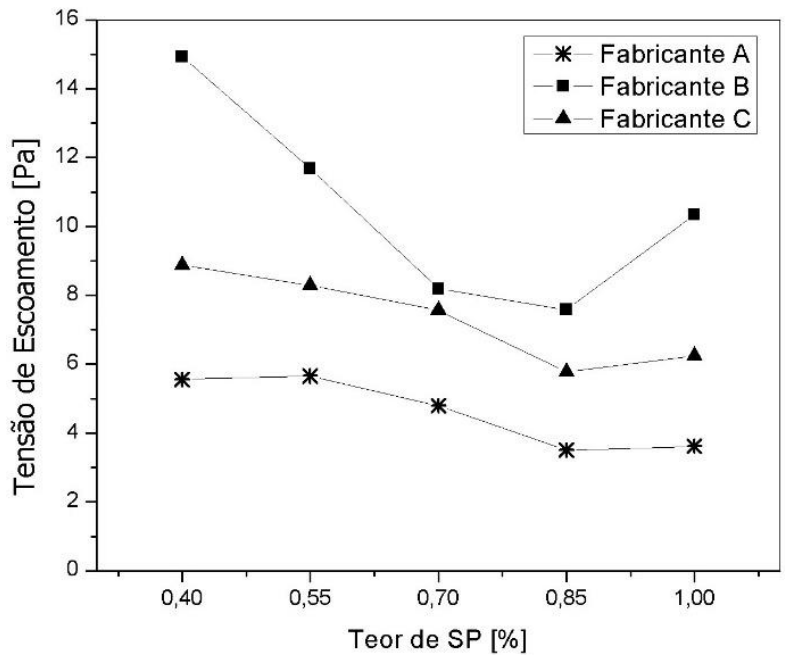

Figura 16: Tensões de escoamento das pastas de CP IV a $25^{\circ} \mathrm{C}$.

O incremento do teor de aditivo até a dosagem de saturação ocasionou a redução da viscosidade plástica e tixotropia das pastas e a tendência inversa observada para os espalhamentos. Embora todos os superplastificantes sejam à base de policarboxilato, os diferentes desempenhos verificados indicam que aditivos de fabricantes distintos influenciam de forma diferenciada os parâmetros reológicos e plasticidade das pastas cimentícias. As dosagens de saturação identificadas tanto pelo método do mini-abatimento quanto por reometria rotacional estão na faixa de teores recomendados pelos fabricantes. $\mathrm{O}$ índice de comportamento $\mathrm{n}$ das pastas com cada aditivo apresentou tendência semelhante para os produtos dos fabricantes A e B, com valores médios de 2,1. Para o fabricante $\mathrm{C}$ o índice médio reduziu em cerca de $10 \%$.

$\mathrm{O}$ produto do fabricante $\mathrm{C}$ apresentou maior homogeneidade em seu desempenho frente às mudanças de temperatura e tipo de cimento Portland aplicado. De modo geral, o aditivo superplastificante multifuncional promove um aumento da fluidez da pasta, porém reduzindo a segregação entre as fases sólida e líquida. Tal efeito reduz a necessidade da utilização combinada do superplastificante a um aditivo modificador de viscosidade, que é prática comum na construção civil.

\section{CONCLUSÕES}

Os resultados e discussões desenvolvidas permitem as seguintes conclusões:

As tensões de escoamento, viscosidades plásticas e tixotropia das pastas cimentícias reduziram em até 60, 61 e 72\%, respectivamente, com um incremento de $20{ }^{\circ} \mathrm{C}$ na temperatura, independente da função do superplastificante (abertura, manutenção ou multifuncional). A temperatura de $45{ }^{\circ} \mathrm{C}$ reduz a capacidade de manutenção da plasticidade com o tempo devido à aceleração dos processos de hidratação dos cimentos.

As formulações com o aglomerante de maior teor de pozolana apresentaram tensões de escoamento, viscosidades e tixotropias superiores em até 80, 70 e 66\%, respectivamente. O aglomerante com mais aluminatos apresentou teores de saturação dos aditivos até $18 \%$ maiores.

Os dados reológicos indicam uma tendência de redução da viscosidade plástica e da tixotropia ao passo que o teor de aditivo aumenta até a dosagem de saturação. O superplastificante A apresentou função de abertura, o B de manutenção e o $\mathrm{C}$ um comportamento intermediário, indicando que os aditivos de diferentes fabricantes, embora apresentem a mesma base, influenciam de forma distinta os parâmetros reológicos e plasticidade das pastas cimentícias. O teor de saturação identificado para todos os aditivos atende às recomendações de uso de seus respectivos fabricantes para as diferentes temperaturas e tipos de cimento aplicados.

\section{AGRADECIMENTOS}

Os autores agradecem ao Conselho Nacional de Desenvolvimento Científico e Tecnológico (CNPq) pelo apoio financeiro. O presente trabalho foi realizado com o apoio da Coordenação de Aperfeiçoamento de Pessoal de Nível Superior (CAPES) em uma parceria entre UFBA e UFRGS, fornecida pelo Programa Nacional de Cooperação Acadêmica (PROCAD). 


\section{BIBLIOGRAFIA}

[1] UYSAL, M., YILMAZ, K., "Effect of mineral admixtures on properties of self-compacting concrete", Cement and Concrete Composites, v. 33, n. 7, pp. 771-776, Aug. 2011.

[2] YEH, I. C., "Modeling slump flow of concrete using second-order regressions and artificial neural networks", Cement and Concrete Composites, v. 29, n. 6, pp. 474-480, July 2007.

[3] CYGAN, G., GOŁASZEWSKI, J., DREWNIOK, M., "The effect of temperature on the properties of fresh self-compacting concrete", Archives of Civil Engineering, v. 62, n. 3, pp. 23-32, Jan. 2016.

[4] NEHDI, M., MARTINI, S. A., "Coupled effects of high temperature, prolonged mixing time, and chemical admixtures on rheology of fresh concrete", ACI Materials Journal, v. 106, n. 3, pp. 231, May 2009.

[5] WINNEFELD, F., BECKER, S., PAKUSCH, J., et al., "Effects of the molecular architecture of combshaped superplasticizers on their performance in cementitious systems", Cement and Concrete Composites, v. 29, n. 4, pp. 251-262, Apr. 2007.

[6] COLLEPARDI, M. “Admixtures - enhancing concrete performance”, In: Proceedings of the International Congress of Global Construction, pp. 55-66, Dundee, UK, 2005.

[7] PLANK, J., ZHIMIN, D., KELLER, H., et al., "Fundamental mechanisms for polycarboxylate intercalation into $\mathrm{C}_{3} \mathrm{~A}$ hydrate phases and the role of sulfate present in cement", Cement and concrete research, v. 40, n. 1, p. 45-57, 2010.

[8] WANG, Q., TAVIOT-GUEHO, C., LEROUX, F., et al., "Superplasticizer to layered calcium aluminate hydrate interface characterized using model organic molecules", Cement and Concrete Research, v. 110, p. 52-69, 2018.

[9] GOETZ-NEUNHOEFFER, F., NEUBAUER, J., SCHWESIG, P., "Mineralogical characteristics of Ettringites synthesized from solutions and suspensions", Cement and concrete research, v. 36, n. 1, p. 65-70, 2006.

[10] CHOMYN, C., PLANK, J., "Impact of different pH-values of polycarboxylate (PCE) superplasticizer solutions on their dispersing effectiveness", Construction and Building Materials, v. 246, p. 118440, 2020

[11] ISAIA, G. C., Concreto: Ciência e tecnologia, v. 1, São Paulo, IBRACON, 2011.

[12] SAKAI, E., YAMADA, K., OHTA, A., "Molecular structure and dispersion-adsorption mechanisms of comb-type superplasticizers used in Japan", Journal of Advanced Concrete Technology, v. 1, n. 1, pp. 16-25, 2003.

[13] KONG, X., ZHANG, Y., HOU, S., "Study on the rheological properties of Portland cement pastes with polycarboxylate superplasticizers", Rheologica Acta, v. 52, n. 7, pp. 707-718, July 2013.

[14] CASTRO, A. L.; LIBORIO, J. B. L.; PANDOLFELLI, V. C., "Reologia de concretos de alto desempenho aplicados na construção civil - Revisão”, Cerâmica, v. 57, n 341, pp. 63-75, Mar. 2011.

[15] BRITO, W. D. S., BRUM, S. M., SILVA, A. L. M. F., et al., "Avaliação do comportamento reológica e mecânico de geopolímero sintetizado com reaproveitamento de resíduo", Revista Matéria, v. 23, n. 3, 2018.

[16] SÉRGIO FILHO, J., SINHORELLI, K., MEDEIROS, G., et al., "Estudo da reologia de pastas cimentícias contendo resíduo de tijolo cerâmico moído e metacaulim”, Revista Matéria, v. 25, n. 1, 2020.

[17] MACIEL, G. de F., BARBOSA, M. P., PEREIRA, J. B., "Análise comparativa da tensão limite de escoamento de argamassas por meio da técnica de Pashias e reometria rotacional", Revista Matéria, v. 21, n. 4, p. 866-879, 2016.

[18] MENDES, M., BAUER, E., SILVA, F., “Avaliação dos parâmetros de autoadensabilidade e de reologia do concreto autoadensável”, Revista Matéria, v. 22, n. 4, 2017.

[19] SCHANKOSKI, R. A., PILAR, R., PILEGGI, R., et al., "Avaliação da reologia de concretos autoadensáveis contendo fílers de britagem”, Revista Matéria, v. 22, n. 2, 2017.

[20] CAMPOS, R. S., BARBOSA, M. P., PIMENTEL, L. L., et al., "Influência dos agregados reciclados nas propriedades reológicas e mecânicas do concreto autoadensável”, Revista Matéria, v. 23, n. 1, 2018.

[21] OLIVEIRA, C. O. E., MACIEL, G. D. F., DE CASTRO, A. L., et al., "Impacto do conceito de empacotamento de partículas na dosagem de concretos de alto desempenho", Revista Matéria, v. 23, n. 1, 2018.

[22] PETIT, J. Y., WIRQUIN, E., KHAYAT, K. H., "Effect of temperature on the rheology of flowable mortars", Cement and Concrete Composites, v. 32, n. 1, pp. 43-53, Jan. 2010. 
[23] YANRONG, Z., XIANGMING, K., LIANG, G., et al., "Variations of yield stress of fresh cement pastes in the presence of superplasticizer highlighted by a hydration index", Journal of Materials in Civil Engineering, v. 29, n. 2, pp. 04016215, Sept. 2017.

[24] ZHANG, Y., KONG, X., GAO, L., et al., "Rheological behaviors of fresh cement pastes with polycarboxylate superplasticizer", Journal of Wuhan University of Technology-Materials Science, v. 31, n. 2, pp. 286-299, Apr. 2016.

[25] NEHDI, M., MARTINI, S. A., "Estimating time and temperature dependent yield stress of cement paste using oscillatory rheology and genetic algorithms", Cement and Concrete Research, v. 39, n. 11, pp. 10071016, Nov. 2009b.

[26] SATHYAN, D., BALAKRISHNAN, A. K., MOHANDAS, S. M., "Temperature influence on rheology of superplasticized pozzolana cement and modeling using RKS algorithm", Journal of Materials in Civil Engineering, v. 30, n. 9, pp. 04018221, Sept. 2018.

[27] ERZENGIN, S. G., KAYA, K., ÖZKORUCUKLU, S. P., et al., "The properties of cement systems superplasticized with methacrylic ester-based polycarboxylates", Construction and Building Materials, v. 166, pp. 96-109, Mar. 2018.

[28] HE, Y., ZHANG, X., KONG, Y., et al., "Influence of polycarboxylate superplasticizer on rheological behavior in cement paste", Journal of Wuhan University of Technology-Material Science, v. 33, n. 4, pp. 932-937, Aug. 2018.

[29] AMERICAN SOCIETY FOR TESTING AND MATERIALS, “ASTM C150/C150M-18: Standard specification for portland cement", West Conshohocken, 2018.

[30] AMERICAN SOCIETY FOR TESTING AND MATERIALS, “ASTM C595/C595M-18: Standard specification for blended hydraulic cements", West Conshohocken, 2018.

[31] ASSOCIAÇÃO BRASILEIRA DE NORMAS TÉCNICAS - ABNT, "NBR 16697: Cimento Portland Requisitos", 2018.

[32] AMERICAN SOCIETY FOR TESTING AND MATERIALS, “ASTM C1738/C1738M-18: Standard practice for high-shear mixing of hydraulic cement pastes”, West Conshohocken, 2018.

[33] KANTRO, D., "Influence of Water-Reducing Admixtures on Properties of Cement Paste-A Miniature Slump Test," Cement, Concrete and Aggregates, v. 2, n. 2, pp. 95-102, 1980.

[34] FELEKOĞLU, B., TOSUN, K., BARADAN, B., et al., "The effect of fly ash and limestone fillers on the viscosity and compressive strength of self-compacting repair mortars", Cement and concrete research, v. 36, n. 9, pp. 1719-1726, Sept. 2006.

[35] JAYASREE, C., GETTU, R., "Experimental study of the flow behaviour of superplasticized cement paste", Materials and Structures, v. 41, n. 9, pp. 1581-1593, Nov. 2008.

[36] MONTE, R., "Avaliação de metodologias de ensaio destinadas à verificação da eficiência de aditivos superplastificantes em pastas de cimento Portland", Tese de doutorado, USP, São Paulo, SP, Brasil, 2003.

[37] PUERTAS, F., ALONSO LÓPEZ, M. M., VÁZQUEZ, T., "Influencia de aditivos basados en policarboxilatos sobre el fraguado y el comportamiento reológico de pastas de cemento Portland", Materiales de Construcción, v. 55, n. 277, pp. 61-73, Mar. 2005.

[38] AMERICAN SOCIETY FOR TESTING AND MATERIALS, “ASTM C1749-17a: Standard guide for measurement of the rheological properties of hydraulic cementious paste using a rotational rheometer", West Conshohocken, 2017.

[39] BANFILL, P. F. G., "The rheology of fresh cement and concrete - A review", In: Proceedings of the international cement chemistry congress, pp.50-62, Durban, May 2003.

[40] CREMONESI, M., FERRARA, L., FRANGI, A., et al., "Simulation of the flow of fresh cement suspensions by a Lagrangian finite element approach", Journal of Non-Newtonian Fluid Mechanics, v. 165, n. 2324, p. 1555-1563, Dec. 2010.

[41] VANCE, K., KUMAR, A., SANT, G., et al., "The rheological properties of ternary binders containing Portland cement, limestone, and metakaolin or fly ash", Cement and Concrete Research, v. 52, pp. 196-207, Oct. 2013.

[42] GRAM, A., SILFWERBRAND, J., LAGERBLAD, B., "Obtaining rheological parameters from flow test - Analytical, computational and lab test approach", Cement and Concrete Research, v. 63, pp. 29-34, Sept. 2014. 
[43] DE MATOS, P. R., PILAR, R., CASAGRANDE, C. A., et al., "Comparison between methods for determining the yield stress of cement pastes”, Journal of the Brazilian Society of Mechanical Sciences and Engineering, v. 42, n. 1, p. 24, 2020.

[44] JAYASREE, C., GETTU, R., "Experimental study of the flow behaviour of superplasticized cement paste", Materials and structures, v. 41, n. 9, p. 1581-1593, 2008.

[45] SENFF, L., HOTZA, D., REPETTE, W. L., et al., "Rheological characterisation of cement pastes with nanosilica, silica fume and superplasticiser additions", Advances in Applied Ceramics, v. 109, n. 4, p. 213218,2010

[46] SATHYAN, D., BALAKRISHNAN, A. K., MOHANDAS, S. M., "Temperature Influence on Rheology of Superplasticized Pozzolana Cement and Modeling Using RKS Algorithm”, Journal of Materials in Civil Engineering, v. 30, n. 9, p. 04018221, 2018.

[47] ROBERT, C. R., SATHYAN, D., ANAND, K. B., "Effect of superplasticizers on the rheological properties of fly ash incorporated cement paste”, Materials Today: Proceedings, v. 5, n. 11, p. 23955-23963, 2018.

[48] GÜLLÜ, H., "Comparison of rheological models for jet grout cement mixtures with various stabilizers", Construction and Building Materials, v. 127, p. 220-236, 2016.

[49] KHAYAT, K. H., SARIC-CORIC, M., LIOTTA, F., "Influence of thixotropy on stability characteristics of cement grout and concrete", Materials Journal, v. 99, n. 3, pp. 234-241, May 2002.

[50] ASSAAD, J., KHAYAT, K. H., MESBAH, H., "Variation of formwork pressure with thixotropy of selfconsolidating concrete", Materials Journal, v. 100, n. 1, pp. 29-37, Jan. 2003.

[51] CORINALDESI, V., MORICONI, G., NAIK, T. R., "Characterization of marble powder for its use in mortar and concrete”, Construction and Building Materials, v. 24, n. 1, pp. 113-117, Jan. 2010.

[52] FERNÀNDEZ-ALTABLE, V., CASANOVA, I., "Influence of mixing sequence and superplasticiser dosage on the rheological response of cement pastes at different temperatures", Cement and Concrete Research, v. 36, n. 7, pp. 1222-1230, July 2006.

[53] HAFID, H., OVARLEZ, G., TOUSSAINT, F., et al., "Effect of particle morphological parameters on sand grains packing properties and rheology of model mortars" Cement and Concrete Research, v. 80, pp. 44-51, Feb. 2016.

[54] ZINGG, A., WINNEFELD, F., HOLZER, L., et al., "Interaction of polycarboxylate-based superplasticizers with cements containing different $\mathrm{C}_{3} \mathrm{~A}$ amounts", Cement and Concrete Composites, v. 31, n. 3, pp. 153-162, Mar. 2009.

[55] NANTHAGOPALAN, P., HAIST, M., SANTHANAM, M., et al., "Investigation on the influence of granular packing on the flow properties of cementitious suspensions", Cement and Concrete Composites, v. 30, n. 9, pp. 763-768, Oct. 2008.

[56] VIKAN, H., JUSTNES, H., WINNEFELD, F., et al., "Correlating cement characteristics with rheology of paste”, Cement and Concrete Research, v. 37, n. 11, pp. 1502-1511, Nov. 2007.

[57] LARRARD, F., SEDRAN, T., "Mixture-proportioning of high-performance concrete", Cement and Concrete Research, v. 32, n. 11, pp. 1699-1704, Nov. 2002.

[58] SCHEEREN, S. C. S., SALUM, P. D. L., KIRCHHEIM, A. P., et al., "Influência de aditivos superplastificantes a base de policarboxilato na resistência a compressão e propriedades no estado fresco de um cimento Portland tipo I", Revista de Engenharia Civil IMED, v. 4, n. 2, pp. 129-141, Jul. 2017.

[59] LI, S., YU, Q., WEI, J., et al., "Effects of molecular mass and its distribution on adsorption behavior of polycarboxylate water reducers", Journal of the Chinese Ceramic Society, v. 39, n. 1, pp. 80-86, Jan. 2011.

[60] OUALIT, M., IREKTI, A., MELINGE, Y., "Saturation point of superplasticizers determined by rheological tests for self compacting concrete", Periodica Polytechnica Civil Engineering, v. 62, n. 2, pp. 346352, Jan. 2018.

\section{ORCID}

Ana Rita Damasceno Costa Angela Borges Masuero Jardel Pereira Gonçalves https://orcid.org/0000-0001-8526-0036

https://orcid.org/0000-0001-9117-8346

https://orcid.org/0000-0003-3484-3869 